\title{
Deseo, cuerpo y afectos: Spinoza bajo la tesis de la producción del espacio de Lefebvre ${ }^{1}$
}

\author{
Desire, body and affects: Spinoza under
}

Lefebvre's space production thesis

DANIELA CÁPONA GONZÁLEZ (DDª

\section{Resumen}

La relación entre Henri Lefebvre y Baruch Spinoza no es del todo evidente, si bien el filósofo francés critica en más de una ocasión la teoría del espacio que deriva de lo planteado a partir del atributo de la extensión del filósofo holandés, esta crítica no erige un absoluto que niegue vínculo alguno desde otras perspectivas. Es precisamente a partir de los conceptos de cuerpo, deseo, afectos y espacio que se puede leer en clave spinoziana la teoría de la producción espacial, en cuanto tras de ésta lo que opera es una lógica del cuerpo y la sensibilidad, que Lefebvre al final de su vida terminará considerando desde la óptica del ritmoanálisis. En el presente se establecerán cautivamente los vasos comunicantes que permitirían conjugar un pensamiento común a partir del vínculo o complementariedad de las categorías planteadas.

Palabras clave: Espacio. Afectos. Exteriorización. Deseo. Cuerpo. Sensibilidad.

\section{Abstract}

The relation between Henri Lefebvre and Baruch Spinoza is not evident at all, it's true that the French philosopher critics in more than one occasion the space theory that results of the statement of the extension attribute of the Dutch philosopher, but that critic is not quite

\footnotetext{
${ }^{1}$ Publicación enmarcada en el proyecto ANID/ Doctorado Nacional/ 2018 - Folio 21181516.

a Universidad de Chile, Santiago, Chile. Dra. (c) en Filosofía, mención Estética y Teoría del Arte, e-mail: dcapona@gmail.com
} 
absolute to deny any approach from another points of view. It is precisely since the concepts of body, desire and space that can be read, in Spinozist key, the space production theory, as to what is it is basis is a logic of body and sensibility, that Lefebvre at the end of his life will end up considering from the rhytmoanalysis optic. In the present article it will be stablish -prudently- the communicating vessels that would allow to combine a common thought from the relation or complementarity between the categories already stablished.

Keywords: Space. Affects. Externalization. Desire. Body. Sensibility.

\begin{abstract}
"El cuerpo se revela como algo desconocido y despreciado. Salvo Espinosa, los filósofos han ignorado desde Sócrates el cuerpo y su riqueza, sus órganos como portadores de sentidos y de valores. Solo Espinosa captó la identidad de lo concebido, de lo percibido, de lo vivido; el cuerpo contiene mucho más que un espacio relleno de materia; contiene lo infinito, lo eterno" (LEFEBVRE, 2016, p. 213).
\end{abstract}

En este pequeño párrafo Henri Lefebvre sitúa la teoría de los afectos y del cuerpo de Baruch Spinoza como única; en ella, lo que en la dialéctica espacial configuraba las prácticas espaciales, las representaciones del espacio y los espacios de representación en correlación a lo concebido, lo percibido, y lo vivido, se encuentra identificado en la noción de cuerpo. Ahora bien, ¿cómo se pueden vincular ambas formulaciones? Los análisis planteados por Henri Lefebvre respecto de la producción del espacio entrañan como base una postulación esencial respecto del cuerpo y el deseo, pues si el espacio es un producto social, la medida de tal producción es el cuerpo, cuya espacialización responde ontológicamente al movimiento del deseo como afirmación de la esencia en la existencia en el acto de producir, el cual es una producción de sí mismo, del otro y del mundo objetivo. Es decir, la producción del espacio es a la vez la producción del cuerpo y la sensibilidad, es la producción del hombre por sí mismo -en términos del Marx de los Manuscritos de economía y filosofía de 1844-, y que no es sino la concreción del deseo como motor de la producción de la vida, o también, de la vida que crea vida, es decir, la vida como afirmación, cuestión que Lefebvre trató brevemente en un texto descubierto hace pocos años titulado Vers une architecture de la Jouissance. En este punto radica la importancia central que otorga Lefebvre al concepto acuñado por Marx de apropiación y valor de uso; precisamente a partir de estas 
categorías el filósofo francés pretende impugnar la escisión entre cuerpo y mente, sujeto y objeto, con el fin de alcanzar la unidad de aquello que, según él, Occidente separó, no sólo al desdeñar el cuerpo, sino también al instaurar la división del trabajo y el trabajo abstracto, separando la producción de lo producido, y por ende separando al hombre del espacio y de sí mismo.

En esta línea argumentativa lo que plantea Lefebvre tiene resonancias spinozistas en lo que respecta a dos conceptos: deseo y cuerpo, pero entrañando una concepción espacial en Spinoza que no se relaciona con un análisis a partir del atributo de extensión -cuestión que el mismo Lefebvre critica al filósofo holandés (2013, p. 63, p. 130, p. 217-219, p. 320-321)-, sino más bien un análisis desde la misma teoría del cuerpo y los afectos como formas de espacialización en virtud de las cuales éstos producen su espacio. En virtud de esto, lo que se pretende analizar en el presente es: 1. El concepto de deseo y afecto en Spinoza, mediada por la tesis de la producción del espacio, 2. El ritmoanálisis desde la perspectiva de la física de los cuerpos del filósofo holandés y 3. La Jouissance y la cupiditas contra la opresión de los espacios de representación, o la crítica a la regulación afectiva de lo social.

\section{¿Qué es lo que puede un cuerpo?: Deseo y afectos en la producción del espacio}

La sentencia de Spinoza que afirma "nadie, hasta ahora, ha determinado lo que puede el cuerpo" (SPINOZA, 2009, E, III, Prop. II, Esc. p.197) abrió durante el siglo XX una línea de pensamiento que antaño no quería ser reconocida. Esta afirmación entraña una crítica a la sobrevaloración del alma, pero también una crítica a la manipulación de las imágenes que conducen a la sumisión, que se expresa en el orden tanto de la subjetividad como de la sensibilidad en virtud de la estandarización de las prácticas sociales. Desde la óptica de los estudios filosóficos, una de sus líneas ha erigido hoy a Spinoza como un filósofo contemporáneo cuya teoría permitiría repensar las condiciones políticas actuales en aras de posicionar líneas de fuga a las relaciones de 
poder y dominación. Ahora bien, ¿qué es lo que puede un cuerpo? ¿por qué esta pregunta es ipso facto, una pregunta política? Precisamente porque en ellos comparece la acción y pasión de los afectos, transformando la naturaleza del alma y las disposiciones del cuerpo acorde a la heteronomía afectiva que se plantea desde el exterior -en un grado de conocimiento imaginativo-, pudiendo ser este exterior manipulado en orden a conseguir adecuar la forma en que los hombres piensan, actúan y padecen, para reproducir el sistema de poder imperante. Escindir al cuerpo es escindir al mismo tiempo el pensamiento y también la potencia, es una escisión que contiene claras pretensiones políticas en pos de la dominación social, de allí su importancia.

Se podría decir que el cuerpo -y también la mente- en Spinoza actúa sólo en virtud del deseo, en cuanto este es definido por el filósofo como "el apetito acompañado de la conciencia del mismo” (SPINOZA, 2009, E, III. Prop. IX. Esc. p. 205-206), cuestión que plantea en el marco de la proposición que afirma que "El alma, ya en cuanto tiene ideas claras y distintas, ya en cuando las tiene confusas, se esfuerza por perseverar en su ser con una duración indefinida, y es consciente de ese esfuerzo suyo" (2009, E, III. Prop. IX. p. 205). De esta manera, Spinoza sitúa al deseo no sólo como uno de los afectos primigenios y principales, sino también como la esencia de los modos finitos, siendo posteriormente identificado con el concepto de potencia y de virtud. Lo que recalca esta proposición es que el conatus persevera independiente del tipo de conocimiento que se tenga, no hay criterio epistemológico que rija la lógica del conatus, lo que hay es consciencia de tal esfuerzo y, por ende, búsqueda de mayor potenciación para afirmar la existencia como grado de potencia. Ésta se busca en los afectos alegres y por ende en el comercio activo o afirmativo con otros cuerpos, que, en su acumulación y desarrollo cualitativo, es decir, en la posesión formal de la potencia de obrar, permitirá el ascenso a los otros géneros de conocimiento. En este sentido, y siguiendo la lectura de Laurent Bove (2009), hay una estrategia que sigue una lógica de placer/displacer propia del conatus. Bajo ésta, el conatus se dispone a ciertos encuentros para así potenciar su esencia, sin embargo, ante los embates y heteronomía de los encuentros que dislocan su potencia, el conatus evita, o bien se resiste a ser aminorado 
por tales cuerpos exteriores. Por ello el filósofo holandés puede definir el amor y el odio: "el amor no es sino la alegría, acompañada por la idea de una causa exterior, y el odio no es sino la tristeza, acompañada por la idea de una causa exterior" (2009, E, III, Prop. XIII, Esc, p. 210). El criterio en virtud del cual se desenvolverá el conatus será el de la búsqueda de placer como búsqueda de potenciación y finalmente, de amor, y el rechazo del displacer como aquello que reprime su esencia, este sería el criterio en virtud del cual se regiría la lógica del conatus y del deseo, a partir de la estratificación de los encuentros con otros cuerpos, pero, en tanto sumido en la imaginación, es decir, sin conocer las causas reales de tales encuentros, esta búsqueda de potencia puede conducir efectiva y paradójicamente a la impotencia.

En este sentido, el cuerpo se haya en una situación de codependencia: en primer lugar, el cuerpo recibe los afectos de los cuerpos exteriores en una situación de heteronomía, a partir de los cuales el conatus y la cupiditas, en su rol estratégico, los direccionan en la medida en que la imaginación y la razón lo permiten, hacia una lógica del placer o una lógica amorosa en búsqueda de potencia, es decir, de autonomía respecto de su capacidad de actuar y pensar. En segundo lugar, el cuerpo actúa en virtud de su propio deseo en tanto inmanente; el deseo que se desea a sí mismo y que en términos jurídicos se plantea como deseo de ser sui juris, pues como afirma Spinoza, "nosotros no intentamos, queremos, apetecemos ni deseamos algo porque lo juzguemos bueno, sino que, al contrario, juzgamos que algo es bueno porque lo intentamos, queremos, apetecemos y deseamos" (2009, E, III. Prop. IX. Esc. p. 206). De esto se sigue que el deseo en sí mismo considerado es anterior al deseo objetual: no se desea en virtud de los objetos o cuerpos, sino en virtud de sí mismo como aumento de potencia. Si bien el deseo y lo deseado se identifican, lo primigenio del deseo es desearse a sí mismo, luego procede el deseo objetual que vendría a apoyar a este primer deseo, claramente en un principio desde un punto de vista imaginativo, y por ende, inadecuado e incluso nocivo para la consecución de la potencia. Sólo desde el punto de vista de la razón y la ciencia intuitiva el deseo podrá desplegarse en total afirmación de sí en virtud del amor intelectual a Dios y el conocimiento sub specie aeternitatis. 
En la proposición XIII del II libro de la Ética, Spinoza afirma: "El objeto de la idea que constituye el alma humana, es el cuerpo, o sea, cierto modo de la extensión que existe en acto, y no otra cosa” (2009, E, II. Prop. XIII p. 130). En esta proposición radica la diferencia primordial entre la teoría spinoziana del cuerpo y aquella planteada por Descartes y su dualismo entre res cogitans y res extensa, cuestión que el mismo Spinoza patentiza en el prefacio del libro V de la Ética de manera crítica. ¿Qué quiere plantear el filósofo holandés con esta afirmación? Al ser el cuerpo el objeto del alma Spinoza plantea la disolución de cualquier tipo de dualismo: cuerpo y mente expresan de distinta forma la esencia de Dios, pues sólo de esta forma los afectos podrían estar en Dios y por lo tanto, también en nuestra alma. Esto implica que todo conocimiento está mediado por los afectos y la corporalidad, cambiando el criterio epistemológico y ontológico de la modernidad. A partir de esto, Spinoza en el corolario de la misma proposición afirma: "De donde se sigue que el hombre consta de alma y cuerpo y que el cuerpo humano existe tal como lo sentimos". Esta afirmación es clave para comprender el rol de los afectos y lo sensible: el cuerpo humano existe tal como lo sentimos pues éste se exterioriza en virtud de los afectos y las ideas que se constituyen en virtud de estos. En este sentido, Spinoza plantea la realidad del cuerpo no como una disminuida, sino como una atravesada por una sensibilidad objetiva, pues "el alma humana percibe, junto con la naturaleza de su propio cuerpo, la de muchísimos otros" y "las ideas que tenemos de los cuerpos exteriores revelan más bien la constitución de nuestro propio cuerpo que la naturaleza de los cuerpos exteriores" (2009, E, II. Prop. XVI. Cor. I y II. p. 139). Por este motivo, el alma para concebir su propio cuerpo requiere de la afección, afectación y comercio con otros cuerpos, necesita componer relaciones que permitan la afirmación del deseo, al mismo tiempo que alejarse de aquellas que lo descomponen en un proceso de individuación en transindividualidad, como establecen Balibar y Morfino. De esto se deduce que la corporalidad se espacializa materialmente en el comercio con otros cuerpos exteriores, y de esto depende la actividad del alma, en cuanto el cuerpo es su objeto, pues 
cuanto más apto es un cuerpo para hacer o padecer más cosas a la vez, más apta que las demás es su alma para percibir a la vez más cosas. Y cuanto más dependen de él solo las acciones de un cuerpo, y menos concurren con él en su acción otros cuerpos, tanto más apta para entender distintamente es su alma. (2009, E, II. Prop. XIII. Esc. p. 129)

Lo cual también lo patentiza Spinoza al afirmar que: "El alma humana es apta para percibir muchísimas cosas, y tanto más apta cuanto de más maneras pueda ser dispuesto su cuerpo" (2009, E, II, Prop. XIV. p. 137). La interacción con otros cuerpos es el primer paso para elaborar no sólo el mundo objetivo y el conocimiento (inadecuado) del alma respecto del cuerpo $-\mathrm{o}$ más bien de sus afecciones, para tener una idea de él-, es también la forma en que el cuerpo mismo se espacializa en cuanto los afectos transforman su naturaleza y disposición frente a los demás cuerpos exteriores, generando cambios en la ratio de movimiento y reposo del propio cuerpo, además de incidir en la forma en que éstos desarrollan sus posteriores relaciones con otros cuerpos, en virtud de la memoria que el cuerpo recoge de estos encuentros.

Ahora bien, para Lefebvre es el cuerpo el que está tras el análisis de la producción del espacio, como afirma Stanek respecto del filósofo francés: "el cuerpo es el modelo mismo de la producción del espacio, al mismo tiempo material, experimentado, representado e imaginado" (LEFEBVRE, 2014, p. LII). El filósofo francés se pregunta,

Antes de producir efectos en lo material (útiles y objetos), antes de producirse (nutriéndose de la materia) y antes de reproducirse (mediante la generación de otro cuerpo), cada cuerpo vivo es un espacio y tiene su espacio: se produce en el espacio y al mismo tiempo produce ese espacio. Es una relación notable: el cuerpo, con sus energías disponibles, el cuerpo vivo, crea o produce su propio espacio; inversamente, las leyes del espacio, es decir, las leyes de discriminación en el espacio, gobiernan al cuerpo vivo así como el despliegue de sus energías (2013, p. 218).

En este punto cobra sentido la tesis de que "El espacio (social) es un producto (social)" (LEFEBVRE, 2013, p. 86), pues es el cuerpo -tanto individual como en su concepción macro, como cuerpo social- el que determina la configuración (ontológica) del espacio. De allí también la importancia del pensamiento nietzscheano en la concepción espacial del filósofo francés, pues es a partir de su valorización del cuerpo, que él puede proyectar en su crítica a la actual configuración espacial una pretensión 
política emancipadora. En tanto la corporalidad remite a un aspecto dionisiaco, a la apropiación, el uso y la fiesta, su fragmentación es la que posibilita aquella inferida al espacio; podría decirse que la primera opera como condición de posibilidad de la segunda. No se trata sólo de su desmembramiento, en virtud de sus funciones y el trabajo que puedan realizar, sino más aún su escisión respecto de la naturaleza y de los productos de su trabajo, la escisión respecto de sí mismo. El cuerpo descuartizado, desmembrado, es la expresión de la propia impotencia que remite al deseo (cupiditas) a su consideración como carencia infinita, y ya no como potencia ontológica -el deseo como modo de pensar, afirma la propia potencia y a la vez la de Dios-, es decir, en términos spinozianos, como desiderium (SPINOZA, 2009. E, III. D.A. 32, p. 273/ CAPONA, 2020).

La inteligencia del cuerpo a la cual apela Lefebvre es aquella que en su devenir histórico y en virtud del desprecio del cuerpo permitió al hombre situarse en el espacio bajo un criterio de utilidad instrumental, esto es lo que configurará la producción espacial para luego, esta misma determinarlo a él. Si se considera la dialéctica espacial, es el cuerpo el que determina la práctica espacial con sus gestos y movimientos, lo mismo ocurre con los espacios de representación, en donde el cuerpo se revitaliza en tanto considerado en su cualidad energética. Pero son las representaciones del espacio en su índole ideológica las que han relegado esta inteligencia, que, en la historia de la configuración espacial, se han sobrepuesto a la dinámica inmediata entre cuerpo y espacio, estableciendo un orden del discurso -propiamente tal, el moderno- que domina al cuerpo en pos de la estratificación del espacio al servicio del poder del capital. Y esto lo hace mediante la instauración de su concepción abstracta. Esto cobra importancia en tanto que, si lo que subyace a la producción espacial es el cuerpo, el cuerpo que es obra y por ende valor de uso y apropiación, es sólo en cuanto éste reanuda su vínculo inmediato con el espacio, cuando la potencia es reapropiada, es decir, en cuanto deja de considerarse como mercancía, cuestión que ocurre con la instauración del trabajo abstracto. De esta manera, lograr la valorización del cuerpo y su autonomía respecto de las representaciones que lo subyugan a un estatismo es 
lograr que sea la potencia social la que determine la espacialidad. Ahora bien, ¿qué es lo que permitiría eso? Lefebvre responderá la Jouissance, la cual puede enmarcarse en el ritmoanálisis.

\title{
El ritmoanálisis desde la perspectiva de la física de los cuerpos de Spinoza
}

\begin{abstract}
El ritmoanálisis, eventualmente, sustituiría al psicoanálisis: más concreto, más eficaz; más cercano a una pedagogía de la apropiación (del cuerpo, de la práctica espacial). Aplicaría al cuerpo vivo y a sus relaciones internas-externas los principios y leyes de una ritmología general. Este conocimiento trataría como campo privilegiado y terreno experimental la danza y la música, las «células rítmicas», sus efectos. (...). (LEFEBVRE, 2013, p. 249-250).
\end{abstract}

Lefebvre toma este concepto de Bachelard, quien a su vez lo descubre en el brasileño Lucio Alberto Pinheiro dos Santos, sin embargo, a juicio del francés, ninguno de ellos lo profundiza. El ritmoanálisis tiene como centro el cuerpo, puesto que él "consiste en un ramillete de ritmos, diferentes pero en melodía (...) el cuerpo produce una guirnalda de ritmos" (LEFEBVRE, 2015, p. 30), en este sentido, podría decirse que los cuerpos, tal como para Spinoza, se rigen por un criterio de movimiento, pero desde una óptica orgánica y no mecánica. El filósofo francés distingue diferentes tipos de composición rítmica: la eurritmia, que mantiene una asociación de salud entre los ritmos, definido por la normalidad y cotidianidad; la arritmia, que corresponde a una configuración disturbada de estos, implicando un estado patológico y de sufrimiento, y en la cual "la discordancia de los ritmos lleva a organizaciones previamente eurítmicas hacia el desorden fatal" (2015, p.25). Por otra parte, la isorritmia se presenta como igualdad o equivalencia rítmica, y finalmente la polirritmia define a toda composición de diversos ritmos como el cuerpo mismo (2015, p. 25).

El ritmoanálisis es una metodología que pone la sensibilidad como punto de partida para analizar distintas prácticas y saberes que configuran los ritmos de los cuerpos, tanto a nivel individual como colectivo, es una herramienta de análisis que permite ampliar y abarcar distintas formas de análisis antaño separadas, pues aborda la 
vida misma. De esta manera, si bien, el énfasis está puesto en el tiempo, se trata de una temporalidad ligada al espacio en cuanto el cuerpo requiere para sí espacializarse, y esto lo hace mediante el movimiento y por tanto, la temporalidad. El cuerpo en tanto ritmo y composición de ritmos, está inserto en el espacio urbano, y está sometido a la temporalidad instrumental del reloj, de las horas laborales -también de la división del trabajo-, familiares, de ocio, etc. El cuerpo posee ritmos singulares pero que se someten a un ritmo colectivo, aquel impuesto por el orden del capital, es decir, en el ritmo se acogen unidad y diferencia, medida y repetición. Como afirma Kurt Meyer:

\begin{abstract}
El desastroso rol del capital no consiste en primer lugar en haber producido al rico y al pobre, al propietario y al no propietario. Consiste más bien en su imperioso desprecio por el cuerpo y el tiempo vivido. Producción y destrucción forman el ritmo inherente del capital. El capital produce todo: cosas, seres humanos y personas. Produce efectos destructivos con guerras e intervenciones brutales, progreso y especulación. (...) Es capaz de controlar el posible desarrollo humano (los ritmos) de todos aquellos sirviéndolo. Esto es oficialmente llamado "movilización" (...). También está la movilización en tiempos de paz: la sujeción de la vida a las reglas de la máquina (2008, p. 151-152).
\end{abstract}

El ritmoanálisis se ofrece como una estrategia de análisis de los cuerpos que se espacializan y crean espacio mediante la composición de un movimiento común, que puede variar según la intensidad que estos adquieran en su relación, generando las variables ya mencionadas, y que pueden permitir una comunicación de movimiento más armónica, o bien incluso llevarla a la descomposición de la relación. Todo cuerpo como ritmo, requiere un comercio afectivo y de movimiento respecto de otros cuerpos, allí está la heteronomía afectiva e imaginativa operando. A este respecto, la física spinoziana responde a un criterio similar en lo que respecta a la teoría de los cuerpos planteada en el II libro de la Ética. En ésta, el filósofo holandés proyectará seis postulados respecto del cuerpo humano, en los cuales expresa que:

I. El cuerpo humano se compone de muchísimos individuos (de diversa naturaleza), cada uno de los cuales es muy compuesto.

II. Algunos individuos de los que componen el cuerpo humano son fluidos; otros, blandos, y otros, en fin, duros.

III. Los individuos que componen el cuerpo humano (y, por consiguiente, el cuerpo humano mismo) son afectados de muchísimas maneras por los cuerpos exteriores.

IV. El cuerpo humano necesita, para conservarse, de muchísimos otros cuerpos, y es como si éstos lo regenerasen continuamente. 
V. Cuando una parte fluida del cuerpo humano es determinada por un cuerpo externo a chocar frecuentemente con otra parte blanda, altera la superficie de ésta y le imprime una suerte de vestigios del cuerpo externo que la impulsa.

VI. El cuerpo humano puede mover y disponer los cuerpos exteriores de muchísimas maneras. (2009, E, Il. Postulados, p. 137)

En virtud de esto, Spinoza plantea una física de los cuerpos -que es a la vez una física del pensamiento, recurriendo a Zourabichvili- enmarcada en una ontología relacional, en donde todos estos se encuentran interconectados no sólo en virtud de la teoría de los individuos compuestos -siendo el cuerpo humano uno de estos, junto con la misma sociedad-, sino también en virtud de los afectos y del criterio de movimiento que establece en los axiomas que rigen esta lógica, cada uno singular pero al mismo tiempo parte de una totalidad, es decir, en donde se presentan lo uno, lo múltiple y la diferencia. El primero afirma: "Todo cuerpo, o se mueve, o está en reposo" y el segundo dice "Cada cuerpo se mueve, ya más lentamente, ya más rápidamente" (SPINOZA, 2009, E, II. Ax. I y II. p. 130). Estos axiomas revelan que la distinción entre los cuerpos es en razón del movimiento y del reposo y no en razón de la sustancia (SPINOZA, 2009, E, II. Lema I. p. 130), y es por ello también que "todos los cuerpos convienen en el hecho de que implican el concepto de un solo y mismo atributo (...). Además, en que pueden moverse más lenta o más rápidamente, y, en términos absolutos, en que pueden moverse o estar en reposo" (SPINOZA, 2009, E, II. Lema II. Dem. p. 130-131), haciendo del movimiento la matriz de comunicación entre estos cuerpos, es decir, al estar conectados todos estos comunican movimiento o reposo sin perder por ello la unidad de la relación que los mantiene conectados, a menos que tal los conduzca a una descomposición. Sin embargo, tanto para Spinoza como para Lefebvre este movimiento no es nunca mecánico, sino orgánico. Este mismo hará hincapié en esta usual confusión al decir que: "fácilmente se confunde ritmo con movimiento, velocidad, una secuencia de movimientos u objetos (por ejemplo, máquinas). Siguiendo esto, tenemos a atribuir a los ritmos un tono mecánico, dejando de lado el aspecto orgánico de los movimientos rítmicos" (LEFEBVRE, 2015, p. 15-16). Hay en ellos repetición -en Spinoza, en virtud de la memoria y la estrategia del conatus como resistencia activa-, pero por lo mismo también diferencia y singularidad, al 
mismo tiempo que unidad, pues cada alteración en la ratio de movimiento y reposo que un cuerpo exterior ejerce sobre otro cuerpo, produce su transformación adquiriendo éste una nueva constitución. La singularidad viene del hecho que, si bien los afectos y sus definiciones son, podría decirse antisubjetivas (LORDON, 2018, p.13), estos tienen en el ámbito de los modos finitos un rasgo singular y particular en cada cuerpo, pues "un afecto cualquiera de un individuo difiere del afecto de otro, tanto cuanto difiere la esencia del uno de la esencia del otro" (SPINOZA, 2009, E, III, Prop. LVII, p. 257), es decir, dos o más cuerpos pueden ser afectados por un mismo afecto de manera distinta, alterando su naturaleza corpórea y mental de manera singular. O bien, como lo plantea Morfino, los afectos son abstracciones hasta el momento en que entran en relación con los cuerpos exteriores: es el carácter y naturaleza de la relación que vincula cuerpo y afecto lo que determina su singularidad (MORFINO, 2015, p. 37).

Ahora bien, dentro de la ontología inmanente establecida por Spinoza están también inscritos estos cuerpos en movimiento y reposo que establecen encuentros entre ellos, sea de composición o descomposición, por lo que podría interpretarse que, si consideramos esta singularidad, multiplicidad y diferencia de movimientos y reposos como ritmos de los cuerpos que tienen una cualidad energética y expresan un quantum de potencia, estos se desenvuelven de forma no jerárquica y por ende horizontal. De lo cual se deduce que no hay primacía de un ritmo sobre otro a nivel ontológico. Lo que puede haber y hay son grados de potencia rítmica más potentes y más débiles, pero sólo en virtud del hecho que un cuerpo mayormente compuesto tiene mayor potencia que un cuerpo aislado, lo que no implica su subsunción de forma necesaria, pues precisamente a partir de la manipulación de la imaginación, mayor cantidad de cuerpos pueden componerse desde un vínculo imaginario que puede representar mayor poder a partir de la imitación de los afectos-, pero no más potencia.

En virtud de lo expuesto, se sigue que analizar ritmoanalíticamente a los hombres y a la sociedad es analizar la relación que los cuerpos mantienen entre sí al modo de una física, en donde cada cuerpo incide realmente en virtud de una relación de co-dependencia, pues el espacio no es un producto aislado de un individuo, sino un 
producto social que se crea a la par que se constituye el mundo objetivo de los hombres, y estos a su vez, a sí mismos. Es decir, es en virtud de la constitución del mundo objetivo que el espacio se produce en virtud de la producción humana que busca potenciar su existencia, en una clara alusión a la teoría del ser genérico y de la naturaleza inorgánica de Marx (MARX, 2010).

Este aspecto relacional de los cuerpos que constituyen una unidad diferenciada tanto de ritmos o movimientos es una composición en un plano horizontal, sin jerarquías reales -más sí de la imaginación -, pero tal como se ha evidenciado, ésta puede ser modificada en virtud de la manipulación de los encuentros y mediante la imposición de una configuración espacial abstracta, producida también socialmente, pero bajo la sumisión al poder del capital. Como patentiza Camillo Boano:

...un elemento central es que aquellos que controlan la producción del espacio también pueden controlar las relaciones sociales, reproduciéndolas a través del espacio (...) es la idea de que la reproducción del capitalismo y la administración de la vida social, en tanto estéticas estructuradas y dominación política, se desarrolla en el habitar" (BOANO, 2015, p. 214-215).

El control sobre la producción del espacio como producto social viene dada por circunstancias histórico-políticas locales y globales, la sucesiva historia de las configuraciones espaciales han derivado en su consolidación como una abstracta, propia del capitalismo, en donde el espacio se ha sometido a la economía-política y con ello, a la violencia y opresión del capital bajo el signo de la abstracción, la cual busca negar toda diferencia y carácter productivo que no sea a su servicio. Lo cual en términos spinozianos sería comprender al capitalismo como una superstición (TATIAN, 2012, p. 81-82). Esta violencia se ejerce principalmente sobre los espacios de representación, en los cuales reside un núcleo afectivo y desiderativo, en cuanto es el deseo lo que motiva o mueve a los afectos. Es por ello que uno de los efectos del espacio es precisamente desencadenar deseos, impulsarlos, pero en ocasiones este deseo es vaciado, como ocurre en su consideración abstracta (LEFEBVRE, 2013, p. 152, CAPONA, 2017). Por ello el filósofo francés afirma:

Transportados fuera de sí, transferidos, los cuerpos vivos se vacían como por los ojos: reclamos, insinuaciones y seducciones múltiples se movilizan para proponer a los cuerpos vivos los dobles 
de sí mismos, engalanados, risueños y felices... La entrada de informaciones, el flujo incesante de mensajes, se topan con el movimiento inverso: la evacuación en el seno mismo de los cuerpos, de toda vida y deseo" (2013, p. 154).

Esta evacuación del deseo en los espacios de representación es una de las metas de esta configuración abstracta, es su forma de crear representaciones del espacio capaces de manipular y dominar a este componente del espacio. En este punto, hay una vinculación entre el cuerpo y el deseo. El deseo es movimiento y acción situada en el cuerpo y la mente, y es aquí donde yace un componente social que se ofusca a ser domeñado. El deseo busca la satisfacción, la alegría como incremento de potencia y afirmación de la esencia de Dios en la existencia, e incluso, como placer (Jouissance para Lefebvre). Si el espacio tiene una configuración abstracta acorde a la economía-política capitalista, cuyo centro es la segregación de las relaciones que precisamente producen el espacio, su función se afinca primariamente en el cuerpo, en su doble naturaleza. Cuando Lefebvre analiza el aspecto económico para una arquitectura del placer afirma:

\begin{abstract}
La economía del placer asume una profunda transformación: con el uso restaurado en su lugar propio, el espacio se podría ser constituido sobre nuevas bases. Esto asume la existencia de un espacio del placer que es en nada parecido al espacio abstracto: espacio del desarrollo, que utiliza una excavadora para destruir todo aquello que podría resistir, pasiva o activamente. En este espacio, el estatuto del objeto puede ser determinado sólo por su relación con el cuerpo y el estatuto del cuerpo: a ritmos, situaciones carnales" (2014, p. 135).
\end{abstract}

Es decir, lo que plantea el filósofo francés es que la reivindicación del valor de uso implica una revalidación del cuerpo, que es a su vez apropiación de la potencia de pensar y actuar, y sólo mediante tal suceso es posible comprender las relaciones que acontecen en el marco de la ciudad. La relación entre objetos es propia de una sociedad basada en el intercambio mercantil, como lo es el capitalismo; en ésta, la corporalidad se disloca y fragmenta junto con el espacio mismo, y se invoca por el contrario, la genitalidad del poder. En este sentido, la filosofía ha apoyado esta fragmentación en cuanto ha intentado a lo largo de su historia desapegarse del cuerpo y elevar el estatuto de la contemplación y la reflexión. El discurso filosófico ha contribuido a esta fragmentación que tiene como consecuencia la segregación política del cuerpo social, lo que corresponde a la alienación de su potencia. Renegando la corporalidad y el placer, 
ha negado el aspecto material que sustenta efectivamente lo real. No se trata entonces del problema sujeto - objeto, sino del problema del cuerpo y el no-cuerpo, esta dualidad que ha devenido en la historia de la filosofía como un motivo de reflexión a ocultar -con claras excepciones- es lo que hoy debe revitalizarse para erigir su realidad efectiva en el espacio, y con ello poder determinar su producción.

\title{
La potencia de la Jouissance y la cupiditas
}

Ante esto es que el término Jouissance, que Lefebvre plantea para erigir lugares para la reconfiguración del espacio acorde a una revitalización del cuerpo, cobra importancia. Es un concepto crítico, en tanto se contrapone a la visión racionalizante del espacio y de la vida cotidiana, y por ende, a sus procesos de sujeción inherentes al poder del capital. La Jouissance se ofusca a comprender el cuerpo como valor de cambio, a un término de valor contractual, y esto se extiende al espacio. Si bien el filósofo francés utiliza el término francés Jouissance, y no Désir-aclaración que se debe realizar en orden a establecer una visión comparativa con el concepto spinozista de cupiditas-, esta distinción o elección terminológica responde a la utilización de un criterio lacaniano. Tal como afirma Stanek:

\begin{abstract}
En tanto opuesto a la economía del intercambio, la jouissance en el texto de Lefebvre representa la transgresión, expansión y exceso: 'jouissance... es sólo un flash, una forma de energía que se expande, gasta, destruyéndose a sí misma en el proceso'. Esta comprensión de la jouissance está suscrita a la distinción básica del psicoanálisis lacaniano, en donde jouissance se distingue tanto del deseo como del placer: mientras el deseo es una falta fundamental, jouissance es una experiencia corporal del punto límite en donde el placer deja de ser placer; es un placer doloroso; 'jouissance es sufrimiento', escribe Lacan" (LEFEBVRE, 2014, p. LIV).
\end{abstract}

Ahora bien, ¿se podría entender la jouissance de Lefebvre como la cupiditas spinozista, o mejor dicho, se establece entre ambos alguna vinculación? De modo cauto, y manteniendo las diferencias respectivas a ambas concepciones filosóficas, la respuesta es afirmativa. O bien, siguiendo la forma en que se expresa el filósofo francés, se podría decir que la respuesta es sí y no. Sí, en cuanto ambos términos hacen alusión a 
un incremento de la potencia corporal, a la afirmación de aquello que beneficia al cuerpo en términos de apropiación, lo cual en el marco de análisis spinozista, se trata de hacer del cuerpo uno sui juris, junto con el intelecto. Pero más aún, es también aquello que implica una inteligencia, que si Spinoza expresa a partir de su teoría de los grados de conocimiento desde la disposición del cuerpo, para Lefebvre se trata de una inteligencia del cuerpo, antaño destruida por Occidente. Ahora bien, también es un no, en cuanto que ambos términos denominan procesos o formas operatorias que tienen una finalidad distinta, o bien, aplicada a distintos ámbitos. La noción de deseo en Spinoza aparece para comprender la esencia del hombre y dar pie para analizar la teoría de los afectos; el deseo es la forma en que se constituye la individualidad humana como individuación en una transindividualidad, en tanto abierta a los afectos exteriores -con los cuales padece- provenientes de otros cuerpos. La afectividad y su carácter relacional define la individualidad humana y también su carácter social, y por ello también configura una comprensión de la corporalidad unida a un aspecto epistemológico. La Jouissance busca la revitalización del uso, del trato inmediato con el espacio, de manera que esta noción busca la reapropiación del cuerpo en su espacialización. En tanto el cuerpo es y produce espacio, para no verse alienado por su propia producción -en tanto sujeta a un logos instrumental, propio de lo que podríamos denominar, el espíritu de modernidad y por ende, del capitalismo-, para no vaciarse a sí mismo por la fragmentación de su corporeidad respecto de sí misma y del Ego, debe reformular sus prácticas en orden a revitalizar su sensibilidad, debe reconfigurar la discursividad en virtud de actos performáticos que alteren o pongan resistencia a los dogmatismos de la representación del espacio dominante. Esto porque, tal como afirma Lefebvre: "La cuestión aquí se ha tomado de otro modo: explorando la practica social como extensión del cuerpo y eso en el curso de una génesis del espacio en el tiempo y, en consecuencia, de una historicidad considerada como producida" (2013, p. 289). Si bien, cambiar solamente las prácticas espaciales no cambia en su totalidad la configuración espacial, sí permite pensar espacios diferentes a modo de resistencia, y esto en virtud de la disposición del cuerpo a abrirse y componer relaciones con otros cuerpos que 
posibiliten el incremento de la potencia. Atribuirles la capacidad de cambiar todo el orden social-espacial, implicaría erigirlas como un absoluto que reduce la espacialidad a la forma en que los cuerpos se expresan, sin considerar que el cuerpo también se ve constreñido por otras lógicas, como también por determinaciones históricas que producen institucionalidades de orden represivo, sumado también a las ideologías que intentan suprimirlo.

Sin embargo, hay una diferencia radical: la Jouissance, si se la remite directa y puntualmente a la distinción lacaniana no es lo mismo que la cupiditas, pues la primera visión responde a la idea de un placer que en su exceso, se concibe como doloroso, siendo ese punto en donde yacería el contacto con lo real. Para Spinoza en cambio, el deseo en ningún caso implica sufrimiento, incluso si éste es pasivo, pues incluso en esta modalidad el deseo busca afirmar. Si bien el deseo en la imaginación puede tener exceso -al igual que el amor, pero en su consideración pasiva, y no proveniente de la razón (SPINOZA, 2009, E, IV. Prop. XLIV, p. 335)-, éste nunca alberga ningún componente de dolor, porque esto implicaría una disminución en la potencia de obrar que no se corresponde con la pretensión afirmativa de la inmanencia del deseo. Sin embargo, lo que sí puede es afirmar la impotencia, en cuanto los hombres se sitúan la más de las veces, en el horizonte de la imaginación. Esto sería para Spinoza una contradicción entre dos afectos: uno que incrementa contra uno que disminuye la potencia, ante lo cual es el afecto más fuerte el que se sobrepone al otro, o bien una fluctuatio animi. Es en este punto en donde comparece la diferencia más patente entre ambas lecturas. A ésta se suma el hecho de que la Jouissance supone un flash, como menciona Stanek anteriormente, mientras que la cupiditas supone que, en una apropiación formal de la potencia de obrar y ascendiendo al grado de conocimiento más elevado lo que hay es una experiencia de la eternidad, la cual nunca puede tener exceso.

No obstante, el concepto de deseo que Henri Lefebvre utiliza, si bien, pocas veces en su obra, sumado al de Jouissance, convergen en la idea de que el cuerpo mantiene en su configuración relacional con otros cuerpos -en tanto ritmos, velocidades y movimientos-, una ontología relacional ya no sólo del espacio, sino de la 
corporeidad. El cuerpo está abierto a la experiencia, y desde allí sitúa su actuar y producción. Cada cuerpo tiene entonces una particularidad, busca la eurritmia, es decir, su afirmación. Desde esta óptica el deseo se puede definir como una singularidad afirmativa en virtud del grado de apropiación del cuerpo, o que, en tanto sumida a estrategias pasivas, se doblega ante éstas mediante estrategias de resistencia para reconfigurar su potencia, claramente en un marco social pues la individualidad está sometida a una visión del «ser-con», pues el hombre es lo más útil para el hombre (SPINOZA, 2009, E, III, Prop. XVIII. Esc., p. 307). Es por ello que:

\footnotetext{
Espíritu/materia, ideal/real, razón/sinrazón, hombre/naturaleza, naturaleza/cultura, tales contrastes obsoletos son incapaces de establecer un nuevo paradigma; deberían ser reemplazados por cuerpo y no-cuerpo, que implican goce [enjoyment] y sufrimiento, o por apropiado y dominado. Y estas debiesen ser consideradas juntas. De esta manera las condiciones del goce [enjoyment] pueden ser concretamente realizadas". (LEFEBVRE, 2014, p. 151)
}

De aquí también se puede considerar que para Spinoza el dilema no es la tradicional oposición entre imaginación y razón, sino su conjugación, su común-unión. En este sentido, la experiencia ligada al cuerpo y a la imaginación son fundamentales para la razón, y es a partir de ellas que se puede comprender que la exteriorización corporal mediante los afectos y los cuerpos exteriores es no sólo vital, sino que además es determinada -por los otros cuerpos- y es determinante -en virtud del propio cuerpoen la constitución de lo político.

A modo de conclusión, no se puede argüir que este acercamiento implique una influencia directa de Spinoza sobre Lefebvre, sino más bien, se trata de una lectura tamizada por la criba spinoziana para evidenciar una configuración espacial a partir de los conceptos de afectos, deseos y cuerpos -es decir, desde un punto de vista materialista-, la cual se distancia de la lectura usual que se enfoca en la teoría ontológica a partir de los atributos. Esta posibilidad de encuentro entre ambos autores permite considerar la importancia de las experiencias y de la vida cotidiana (CAPONA, 2019), dando luces sobre un posible análisis micropolítico enmarcado desde la particularidad y singularidad de los cuerpos individuales y colectivos. 


\section{Referencias}

BOANO, C. El cuerpo del diseño urbano y de la arquitectura claman por venganza: ritmoanálisis y sus interpretaciones metodológicas. En: MATTOS, C. A.; LINK, F. (Eds.). Lefebure revisitado: capitalismo, vida cotidiana y el derecho a la ciudad. Santiago: RIL Editores- Instituto de Estudios Urbanos y Territoriales UC, 2015.

BOVE, L. La estrategia del conatus: Afirmación y resistencia en Spinoza. Madrid: Tierradenadie Editores, 2009.

CAPONA, D. Deseo, violencia y capital: los espacios de representación en la consideración del espacio abstracto en Henri Lefebvre. Hybris Revista de Filosofía, v. 8, n.1, p.95-126, Mayo 2017.

CAPONA, D. Para una estética de la vida cotidiana: Naturaleza, potencia y cuerpo en Spinoza y Marx. Alpha, Revista de Artes, Letras y Filosofía, v. 2, n. 49, p. 9-24, 2019.

CAPONA, D. La tensión intradesiderativa en Spinoza: tentativas sobre la noción de 'desiderium'. Anales del Seminario de Historia de la Filosofía, v.37, n.1, p.23-35, 2020.

LEFEBVRE, H. Hegel, Marx, Nietzsche (o el reino de las sombras). Madrid: Siglo XXI, 2016.

LEFEBVRE, H. La producción del espacio. Madrid: Capitán Swing, 2013.

LEFEBVRE, H. Rhythmanalysis. Space, time and everyday life. London: Bloomsbury, 2015.

LEFEBVRE, H. Toward an architecture of enjoyment. Minneapolis: University of Minnesota Press, 2014.

LORDON, F. La sociedad de los afectos. Por un estructuralismo de las pasiones. Buenos Aires: Adriana Hidalgo, 2018.

MARX, K. Manuscritos de economía y filosofía. Madrid: Alianza, 2010.

MEYER, K. Rhythms, streets, cities. En: GOONEWARDENA, K.; KIPFER, S.; MILGROM, R.; SCHMID, C. (Eds.). Space, difference, everyday life. Reading Henri Lefebvre. New York: Routledge, 2008. p. 151-152.

MORFINO, V. El tiempo de la multitud. Santiago de Chile: Doble Ciencia, 2015.

SPINOZA, B. Ética. Madrid: Alianza, 2009.

TATIÁN, D. Baruch. Buenos Aires: La cebra, 2012.

RECIBIDO: $21 / 11 / 2019$

APROBADO: $14 / 06 / 2020$

RECEIVED: $11 / 21 / 2019$

APPROVED: 06/14/2020 